\title{
Bit Error Rate Evaluation of MR Heads through a PRML Read Channel
}

\author{
Data Storage Components Business Group \\ TDK Corporation
}

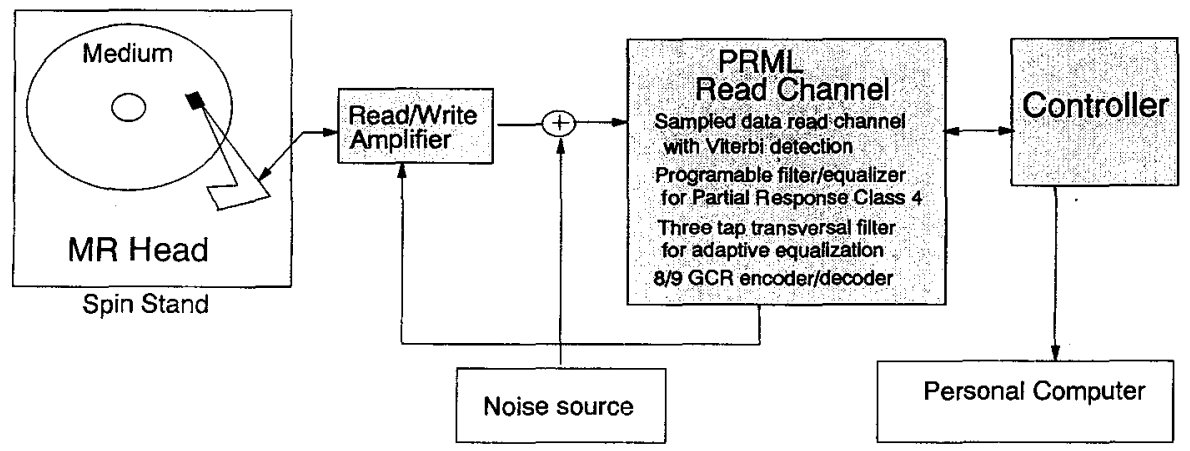

The block diagram of the error rate measuring system with the PRML read channel.

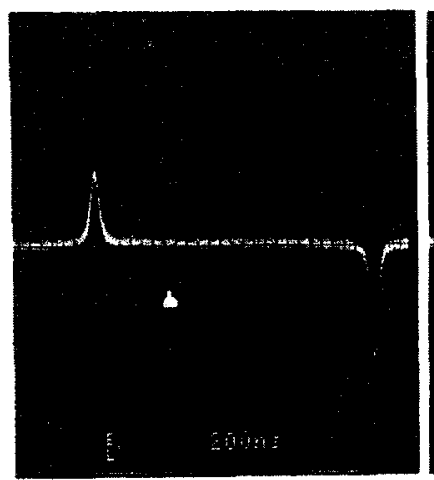

(a) Asymmetry $=-19 \%$

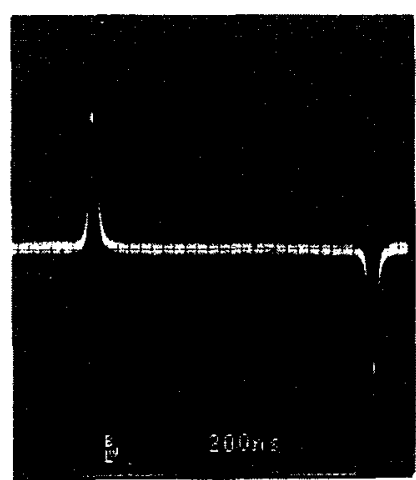

(c) Asymmetry $=+3 \%$

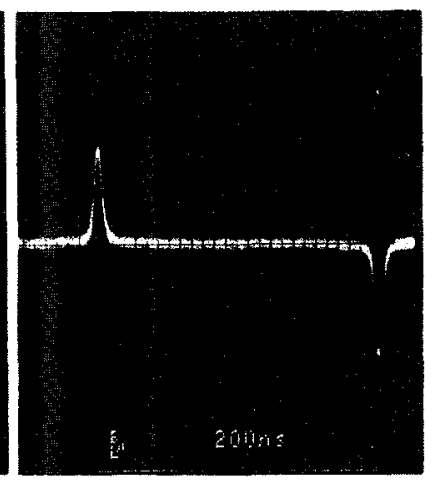

(b) Asymmetry $=-9 \%$

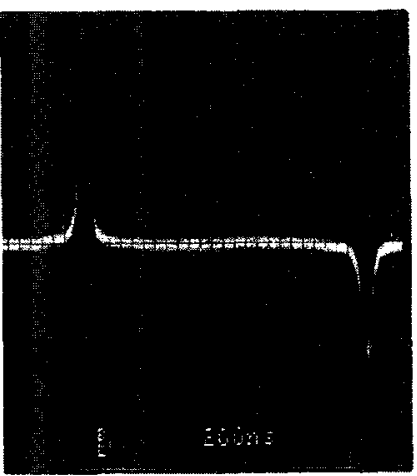

(d) Asymmetry $=+26 \%$

The amplitude asymmetry of the MR heads at the sense current (bias current) of $10 \mathrm{~mA}$. (y : arbitrary).

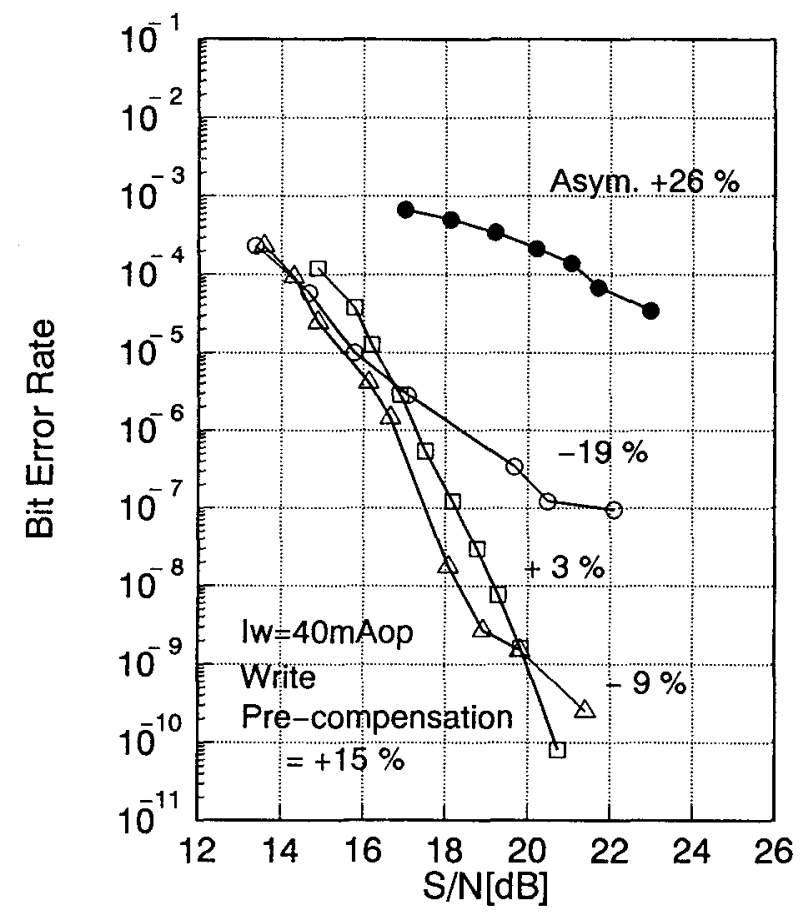

The bit error rate comparison of the MR heads with various amplitude asymmetry ranging from $-19 \%$ to $+26 \%$. 